\title{
Differential expression of proteins in genetically distinct Trypanosoma cruzi samples (Tcl and Tcll DTUs) isolated from chronic Chagas disease cardiac patients
}

Maykon Tavares de Oliveira ${ }^{1}$, Karina Taciana Santos Silva², Leandro Xavier Neves ${ }^{3}$, Max Jean de Ornelas Toledo ${ }^{4}$, William Castro-Borges ${ }^{1,3,5^{*}}$ and Marta de Lana ${ }^{1,6}$

\begin{abstract}
Background: Trypanosoma cruzi, a hemoflagellate protozoan parasite and the etiological agent of Chagas disease $(C D)$, exhibits great genetic and biological diversity. Infected individuals may present clinical manifestations with different levels of severity. Several hypotheses have been proposed to attempt to correlate the diversity of clinical signs and symptoms to the genetic variability of T. cruzi. This work aimed to investigate the differential expression of proteins from two distinct genetic groups of T. cruzi (discrete typing units Tcl and Tcll), isolated from chronically infected individuals displaying the cardiac form of CD. For this purpose, epimastigote forms of the two isolates were cultured in vitro and the cells recovered for protein extraction. Comparative two-dimensional (2D) gel electrophoreses were performed and differentially expressed spots selected for identification by mass spectrometry, followed by database searching and protein categorization.
\end{abstract}

Results: The 2D electrophoretic profiles revealed the complex composition of the T. cruzi extracted proteome. Protein spots were distributed along the entire $\mathrm{pH}$ and molecular mass ranges attesting for the integrity of the protein preparations. In total, 46 differentially expressed proteins were identified present in 40 distinct spots found in the comparative gel analyses. Of these, 16 displayed upregulation in the gel from Tcl-typed parasites and 24 appeared overexpressed in the gel from Tcll-typed parasites. Functional characterization of differentially expressed proteins revealed major alterations associated with stress response, lipid and amino acid metabolism in parasites of the Tcll isolate, whilst those proteins upregulated in the Tcl sample were primarily linked to central metabolic pathways.

Conclusions: The comparative 2D-gel electrophoresis allowed detection of major differences in protein expression between two T. cruzi isolates, belonging to the Tcl and Tcll genotypes. Our findings suggest that patients displaying the cardiac form of the disease harbor parasites capable of exhibiting distinct proteomic profiles. This should be of relevance to disease prognosis and treatment.

Keywords: Trypanosoma cruzi, DTUs, Differential proteomics, Chagas disease

\footnotetext{
*Correspondence: wborges@ufop.edu.br

'Programa de Pós-Graduação em Ciências Biológicas do Núcleo de Pesquisas em Ciências Biológicas (NUPEB), Campus Universitário Morro do Cruzeiro, Universidade Federal de Ouro Preto, CEP, Ouro Preto, MG 35400-000, Brazil ${ }^{3}$ Programa de Pós-Graduação em Biotecnologia do Núcleo de Pesquisas em Ciências Biológicas (NUPEB), Campus Universitário Morro do Cruzeiro, Universidade Federal de Ouro Preto, CEP: 35400-000, Ouro Preto, MG, Brazil Full list of author information is available at the end of the article
}

(c) The Author(s). 2018 Open Access This article is distributed under the terms of the Creative Commons Attribution 4.0 International License (http://creativecommons.org/licenses/by/4.0/), which permits unrestricted use, distribution, and reproduction in any medium, provided you give appropriate credit to the original author(s) and the source, provide a link to the Creative Commons license, and indicate if changes were made. The Creative Commons Public Domain Dedication waiver (http://creativecommons.org/publicdomain/zero/1.0/) applies to the data made available in this article, unless otherwise stated. 


\section{Background}

Chagas disease is caused by the hemoflagellate protozoan parasite Trypanosoma cruzi. According to data from the World Health Organization [1], 6-7 million individuals are infected by the parasite throughout Latin America and around 60-70 million people are at risk of infection. Hampered by the high genetic variability of the parasite, the afflicted population exhibits varying clinical forms of the disease [2-4]. These are mostly refractory to treatment, particularly for chronically infected individuals [5].

It has been established that the natural populations of $T$. cruzi are represented by at least seven discrete typing units (DTUs) TcI-TcVI and Tcbat [6]. Any possible correlation between these DTUs and the occurrence of the different clinical forms observed in chagasic patients is, to date, quite controversial $[7,8]$. Since regulation of gene expression in trypanosomatids operates post-transcriptionally, molecular approaches to analyze and compare the proteomes of $T$. cruzi populations may be fundamental to show the association between their genetic variability and the clinical manifestations of Chagas disease [9].

In this regard, Telleria et al. [5] pioneered the use of 2D-gel electrophoresis to highlight differential protein expression among nine T. cruzi laboratory-cloned stocks. Differences in spot volumes for several proteins allowed the authors to highlight proteomic variability among the clones and their grouping into four distinct DTUs. However, only a few representative spots (nine in total) of major soluble components such as $\alpha$ - $/ \beta$-tubulins and heat-shock proteins were confidently identified by mass spectrometry. This prevented major conclusions to be drawn concerning the biological meaning of the proteomic dissimilarities observed for the distinct DTUs. A more recent approach revealed that mass spectral libraries generated with $T$. cruzi stocks representatives of the distinct DTUs can be used to confidently distinguish among the genotypes [10].

Towards a patient-oriented approach, we have previously reported a range of biological properties associated to $T$. cruzi samples that were isolated from chronicallyinfected individuals displaying the cardiac, indeterminate and digestive forms of Chagas disease. Briefly, blood samples were collected from patients living in Minas Gerais, Brazil, and the recovered parasites genotyped as belonging to DTUs I, II and VI. Marked differences in their biological behaviour were observed when samples belonging to these three DTUs were grown in vitro or used to infect Vero cells [11]. Moreover, in vivo studies of parasitemia, polymorphism of trypomastigotes, cardiac inflammation and fibrosis contributed to pinpoint major differences among those DTUs in the murine model of infection.

In the present study, aiming to provide molecular insights into the dissimilarities observed, we have selected two of those strains belonging to the distinct and phylogenetically polar groups (TcI and TcII) for a comparative 2D-gel electrophoretic analysis. Mass spectrometry identification greatly expanded the number and the cellular processes associated with differentially expressed proteins observed between these two genetic groups. Understanding the role such proteins play during parasitism should be of relevance to disease outcome and treatment, in particular for cardiac chagasic patients.

\section{Methods}

\section{Selection of Chagas disease patients}

The two T. cruzi samples used in this study were isolated from chronic Chagas disease patients (patients code: PR150 and 452), living in different regions in the state of Minas Gerais (MG), Brazil. The PR150 sample (TcI) was isolated from a female patient, living in Januária, northern MG [12], and sample 452 (TcII) was isolated from a patient living in Berilo, Vale do Jequitinhonha, MG [13]. These two locations are geographically separated by $487 \mathrm{~km}$. Both patients presented the cardiac clinical form of the disease (moderate and severe, respectively) and agreed to participate in the Chagas Disease Programme.

The serological diagnosis for T. cruzi infection was confirmed according to the guidelines of the Ministry of Health of Brazil [14] and the WHO [15]. In addition, the patients were evaluated through anamnesis, clinical examination, posteroanterior chest X-ray, contrast-enhanced $\mathrm{X}$-ray of the esophagus and colon, electrocardiogram and echocardiogram. After analyzing the results, the patients were clinically classified according to the Brazilian Consensus on Chagas Disease of 2015 [16].

\section{Obtaining $T$. cruzi isolates}

Trypanosoma cruzi isolates were obtained by using the blood culture technique described by Chiari et al. [17]. Briefly, sterile tubes containing heparin (Vacuntainer BD, New Jersey, USA) were used to collect approximately $30 \mathrm{ml}$ of intravenous blood. The blood was transferred to a conical tube and immediately centrifuged at $2070 \times g$ for $10 \mathrm{~min}$ at room temperature. To the red blood cell (RBC) concentrate obtained, $5 \mathrm{ml}$ of LIT medium [18] was added and followed by a new centrifugation step performed under the same conditions. This procedure was then repeated to obtain a clean leukocyte layer that was removed for culture. The RBC layer was resuspended in $5 \mathrm{ml}$ of LIT medium and subdivided into three new tubes containing $5 \mathrm{ml}$ LIT medium each. These tubes were incubated at $28{ }^{\circ} \mathrm{C}$ and homogenized manually three times a week. One drop of the pellet from each preparation was analyzed under an optical microscope at 30, 60, 90 and 120 days after collection to detect the presence of multiplying parasites. 


\section{Acellular culture of $T$. cruzi}

Trypanosoma cruzi isolates were maintained in exponential growth by successive addition of LIT medium until approximately $35 \mathrm{ml}$ of culture were obtained. The culture was transferred to tapered tubes and centrifuged at $2070 \times g$ at $4{ }^{\circ} \mathrm{C}$ for $30 \mathrm{~min}$. After centrifugation, the supernatant was carefully discarded by inversion and 10 $\mathrm{ml}$ of sterile buffered saline (PBS, $\mathrm{pH}$ 7.2) was added to the pellet. The mixture was subjected to a new centrifugation step as before for $15 \mathrm{~min}$. After repeating this procedure, the pellet was transferred to a pre-weighed $1.5 \mathrm{ml}$ microcentrifuge tube. The pellet was then washed with sterile PBS and centrifuged at $6900 \times g$ for $10 \mathrm{~min}$. The supernatant was carefully removed, the tube reweighed, and the wet mass of parasites stored at $-70{ }^{\circ} \mathrm{C}$ for further proteomic analysis. This protocol was repeated for each of the three biological replicates used in this study.

\section{Protein extraction}

Approximately $100 \mathrm{mg}$ of epimastigote cell pellets were used for the extraction of proteins. The samples were homogenized in $500 \mu \mathrm{l}$ rehydration solution (7 M urea, $2 \mathrm{M}$ thiourea, 2\% w/v CHAPS, $0.002 \% \mathrm{w} / \mathrm{v}$ bromophenol blue; all from Sigma-Aldrich, Missouri, USA) containing $1 \times$ Protease Inhibitor Cocktail (Sigma-Aldrich) at a final dilution of 1:25, for $10 \mathrm{~min}$ in an ice bath. The samples were then sonicated by means of a series of three $15 \mathrm{~s}$ pulses, each followed by $45 \mathrm{~s}$ resting on ice between cycles. Homogenates were centrifuged at $20,000 \times g$ for 1.5 $\mathrm{h}$ at $4{ }^{\circ} \mathrm{C}$ to remove cell debris. The $1 \mathrm{D}$ electrophoretic profiles were used to verify the integrity of the extracts and to normalize, through densitometric analysis (software Quantity one v.29.0), the total amount of protein present in each sample. Briefly, a $5 \mu \mathrm{l}$ aliquot of each sample was separated under denaturing conditions using $12 \%$ SDS-PAGE. After $30 \mathrm{~min}$ in fixative solution $(40 \%$ ethanol/7\% acetic acid), the gel was stained in $0.02 \%$ Coomassie Blue G-250 solution (Sigma-Aldrich) for $2 \mathrm{~h}$.

\section{Two-dimensional gel electrophoresis}

2D-gels were prepared using $150 \mu \mathrm{g}$ of proteins obtained for each isolate. First, a precipitation step was performed on trichloroacetic acid/acetone (1:8), followed by solubilization of proteins in rehydration buffer containing 1\% DTT and 0.8\% ampholytes (pH3-10 NL Buffer IPG; GE Healthcare, Uppsala, Sweden) at a final volume of $250 \mu \mathrm{l}$ for each sample. The first dimension was performed using $13 \mathrm{~cm}$ gel strips (pH3-10 NL, GE Healthcare). Proteins were isoelectrofocalized at $23{ }^{\circ} \mathrm{C}$ using IPGphor 3 (GE Healthcare) according to the following protocol: step 1, $14 \mathrm{~h}$ of passive rehydration; step $2,1 \mathrm{~h}$ at constant $500 \mathrm{~V}$; step 3, gradient up to $1000 \mathrm{~V}$ in $1 \mathrm{~h}$; step 4 , gradient up to $8000 \mathrm{~V}$ for $2.5 \mathrm{~h}$; step 5, held at constant
$8000 \mathrm{~V}$ until making a total of $29,500 \mathrm{~V}$ throughout the isoelectrofocalization protocol. All steps were performed at a maximum current of $50 \mu \mathrm{A}$ per strip. The isoelectrofocalized proteins were then reduced, followed by alkylation using 1\% DTT and 4\% iodoacetamide, respectively, in equilibration buffer (6 M urea, 75 $\mathrm{mM}$ Tris- $\mathrm{HCl} \mathrm{pH}$ 8.8, 29.3\% glycerol, 2\% SDS, $0.002 \%$ bromophenol blue) as described previously [19]. The second dimension was performed at $5{ }^{\circ} \mathrm{C}$ on $12 \%$ SDS-PAGE gel $(18 \times 16 \mathrm{~cm})$ at $20 \mathrm{~mA} /$ gel, for approximately $6 \mathrm{~h}$. The gels were fixed in $2 \% \mathrm{v} / \mathrm{v}$ orthophosphoric acid $/ 30 \% \mathrm{v} / \mathrm{v}$ ethanol overnight, and then washed $3 \times 10 \mathrm{~min}$ with $2 \%$ $\mathrm{v} / \mathrm{v}$ orthophosphoric acid. Staining was performed for 48 $\mathrm{h}$ in a Coomassie colloidal solution containing $2 \% \mathrm{v} / \mathrm{v}$ orthophosphoric acid, $18 \% \mathrm{v} / \mathrm{v}$ ethanol, $15 \% \mathrm{w} / \mathrm{v}$ ammonium sulfate and $0.002 \% \mathrm{w} / \mathrm{v}$ Coomassie blue G-250 (Sigma-Aldrich). Excess stain was removed by washing the gels in $20 \% \mathrm{v} / \mathrm{v}$ ethanol for $5 \mathrm{~min}$ before they were scanned using ImageScanner III (GE Healthcare).

Densitometric analyses of 2D-gels were performed using the SameSpots software (TotalLab Ltd., v.20, UK) following the manufacturer's recommendations. Quantitative analyses were performed on spots that presented $\geq$ 1.5-fold change in comparison to the respective spots found in the gel used as reference (the one from strain 452). The maximum standard deviation allowed per spot, for triplicate gels, was $10 \%$. The spots that met these criteria were selected for protein identification by mass spectrometry.

\section{Protein identification by mass spectrometry and database searching}

Selected spots were manually excised and destained in $40 \% \mathrm{v} / \mathrm{v}$ ethanol $/ 7 \% \mathrm{v} / \mathrm{v}$ acetic acid. After washing in ultrapure water they were submitted to gel digestion according to Helman et al. [20]. The recovered peptides were analyzed on a Q-Exactive hybrid quadrupole-orbitrap mass spectrometer (Thermo Fisher Scientific, Bremen, Germany). Seventeen $\mu$ l of peptide samples were injected into a nanoUHPLC instrument (Dionex UltiMate 3000, Thermo Fisher Scientific) through a trapping system (Acclaim PepMap100, $100 \mu \mathrm{m} \times 2 \mathrm{~cm}, \mathrm{C} 18,5$ $\mu \mathrm{m}, 100 \mathrm{~A}$, Thermo Scientific) for $3 \mathrm{~min}$ using as solvent $98 \%$ water $/ 2 \%$ acetonitrile $(\mathrm{ACN})$ with $0.05 \%$ trifluoracetic acid (TFA) and subsequently directed into a capillary column (Acclaim PepMap100, $75 \mu \mathrm{m} \times 25 \mathrm{~cm}, \mathrm{C} 18,3$ $\mu \mathrm{m}, 100 \mathrm{~A}$, Thermo Fisher Scientific). Reversed-phase separation of peptides was performed at $40{ }^{\circ} \mathrm{C}$ in a gradient of solvent A (water, $0.1 \%$ formic acid) and B (80\% ACN / 20\% water, $0.1 \%$ formic acid), at a flow rate of 0.3 $\mu \mathrm{l} / \mathrm{min}$. Peptides were sequentially eluted over a gradient spanning from $4 \%$ to $15 \%$ of solvent B for $2 \mathrm{~min}$, increasing to $55 \%$ of $\mathrm{B}$ over additional $15 \mathrm{~min}$. Then, peptides were directed to the online coupled mass 
spectrometer by means of a nanospray ionization source. Ions were detected under positive mode through data dependent analysis. Resolution for precursor ions (MS1) was set to 70,000 (FWHM at $200 \mathrm{~m} / \mathrm{z}$ ) with an automatic gain control target of $3 \mathrm{e}^{6}$, maximum injection time of 100 ms, scanning over $300-2000 \mathrm{~m} / z$. The Top10 most intense precursor ions of each MS1 mass spectra were individually isolated with a 2.0 Th window for activation via higher-energy collisional dissociation (HCD) with normalized energy of $30 \mathrm{~V}$. Only peptides exhibiting charge states of $+2,+3,+4$ and +5 were selected. Automatic gain control target was set to $5 \mathrm{e}^{5}$ (minimum accumulation of $3.3 \mathrm{e}^{3}$ ) with maximum injection time of $75 \mathrm{~ms}$. Dynamic exclusion of $15 \mathrm{~s}$ was active.

MS1 and MS2 spectral data were submitted to Proteome Discoverer v.2.1 (Thermo Fischer Scientific) platform, underpinned by the SEQUEST HT searching algorithm, using a compilation of T. cruzi databases downloaded from TriTrypDB (available at http://tritrypdb.org/ tritrypdb/ and containing 21,060 sequences/10,322,012 residues). This combined database contained equivalent number of sequences from TcI- and TcII-typed parasites. Search parameters included cysteine carbamidomethylation as a fixed modification, methionine oxidation as a variable modification, up to one trypsin missed cleavage site, tolerance set to $\pm 10 \mathrm{ppm}$ for precursor and $\pm 0.1 \mathrm{Da}$ for product ions. Only proteins identified with peptides exhibiting expected values $\leq 0.05$, false discovery rate $\leq$ $1 \%$ and percentage coverage $\geq 8 \%$, with at least one unique peptide, were considered in this study. Whenever more than one protein identification were assigned to a single spot, the major component was associated with the higher total Area Under Curve (AUC) observed, and only if the total AUC of a second protein represented at least $40 \%$ of the major area, it was indicated.

\section{Functional categorization of proteins}

The identified proteins were distributed into 9 categories, according to their biological function and termed as follows: transcription and translation, heat-shock response, protein synthesis and degradation, metabolism (related to carbohydrates, nucleotides, amino acids and lipids), cytoskeleton and cell signaling. Gene Ontology information (available at http://geneontology.org/) was used to support the protein categorization.

\section{Statistical analysis}

Data derived from the quantitative proteomic analyses were examined using the Graph Pad Prism software (v.5). The comparison between the two distinct groups of gels was made through ANOVA. The significance level adopted was $P \leq 0.05$.

\section{Results}

Proteomic analysis of epimastigote forms of $T$. cruzi

The protein extracts obtained from three distinct epimastigote samples resulting from the acellular cultivation of each strain (PR150-TcI and 452-TcII) were submitted to isoelectrofocalization and subsequent bidimensional electrophoresis in $13 \mathrm{~cm}$ gel, pH3-10NL. Following Coomassie staining, the gels obtained in triplicates were analyzed using the SameSpots software. Overall, good reproducibility for the gels was achieved, with proteins covering the entire $\mathrm{pH}$ and molecular mass ranges indicating adequate protein integrity following extraction (Fig. 1).

Over 1700 spots were detected, with approximately 200 displaying $\geq 1.5$ fold change for each overlapping gel pair. The comparison among the triplicates revealed 40 matched spots showing $<10 \%$ standard deviation. Among them, 16 protein spots from gel PR150 appeared upregulated relative to their corresponding spots in the gel from strain 452, whereas 24 were found upregulated in gel 452 relative to their respective pairs in gel PR150.

The spots revealing expression differences between strains PR150 and 452 were then excised, digested with trypsin and subjected to protein identification by mass spectrometry. Positive identifications were categorized according to their molecular function as shown in Table 1 (see also Additional file 1: Table S1 for mass spectrometric data related to peptide/protein identifications).

Fold changes in expression for each protein described in Table 1 were represented in a bar plot. As shown in Fig. 2, proteins belonging to diverse functional groups had their levels of expression altered when compared between the two evaluated genotypes. Notably, the representative sample of the TcII genotype (patient 452 exhibiting severe cardiac clinical form) demonstrated differential expression of proteins related to stress response and metabolism of amino acids and lipids. Concerning the representative TcI genotype (patient PR150 exhibiting moderate cardiac clinical form), there was pronounced expression of proteins linked to central metabolic pathways.

\section{Discussion}

Changes in expression of proteins related to stress response are genetically correlated with biological aspects of T. cruzi infection. Among the identified proteins, three presented increased expression in the PR150 (TcI) sample [heat-shock protein 85 (Hsp85), heat-shock protein 60 (Hsp60) and thiol-dependent reductase 1 (TDR1)], and five proteins, known to perform related molecular functions, were also found at higher levels in strain 452 (TcII) [heat-shock proteins 85 and 70 (Hsp85 and Hsp70, respectively), IgE-dependent histamine-releasing factor (HRF), iron superoxide dismutase (SODB) and glutathione peroxidase-like protein (GPX)]. 


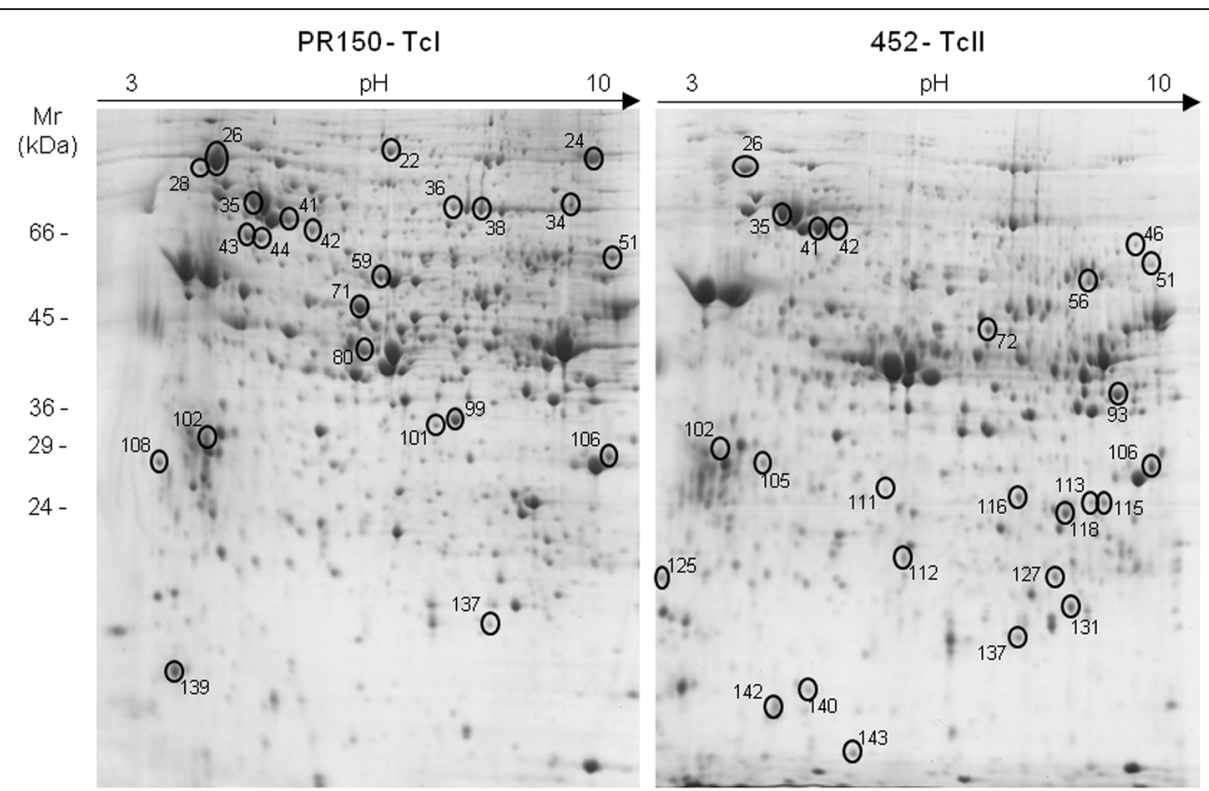

Fig. 1 Comparative two-dimensional gel electrophoretic profiles for samples TCl (PR150) and Tcll (452). Protein fractions from both samples were isoelectrofocalized on a $13 \mathrm{~cm}$ pH3-10NL IPG strip and subsequently proteins separated according to their molecular masses using $12 \%$ SDSPAGE. After Coomassie staining, the gel images were aligned using the SameSpots software for identification of differentially expressed spots (numbered). These were then processed for in gel digestion and the resulting peptides submitted to mass spectrometric identification. The figure is a representative of a pair of gels

As for heat-shock proteins, Urményi et al. [21] reviewed their relevance in the context of T. cruzi biology. It is known that this protozoan parasite has a complex life-cycle involving invertebrate and vertebrate hosts being subject to several types of stress. Thus, molecular chaperones and proteases are highly expressed in order to assist in the maintenance of cellular homeostasis. Some families of HSPs, especially Hsp70, Hsp90, Hsp100, Hsp40 and small HSPs, have conserved and unique sequences for T. cruzi and demonstrate specific expression patterns among the different strains. In addition, the different expression patterns observed are relevant to parasite biology, particularly concerning resistance to treatment [21, 22]. It has also been demonstrated that parasites expressing higher levels of HSPs have a greater capacity to transit between the wild and domestic cycle of Chagas disease, since they present greater multiplication and metacyclogenesis in the triatomine vector. This favors an enhanced capacity for infection of the vertebrate hosts (man and domestic/wild animals) through the mechanism of natural transmission. This family of proteins has been associated with mechanisms of intracellular survival, metacyclogenesis and virulence [21, 23-25].

According to previous work by our research group, PR150 (TcI) and 452 (TcII) strains have demonstrated capacity to infect Vero cells [11]. However, when we compared the infection in the murine model, only strain 452 (TcII) was able to infect mice and generate patent parasitemia. This might be related to a higher expression of heat-shock proteins and other molecules related to stress resistance shown herein. Several studies have reported that TcII parasites isolated from humans are, in fact, the most likely to infect and present patent parasitemia in mice $[26,27]$. Therefore, they are more capable of infecting vectors in view of this characteristic and the predominance of larger blood trypomastigotes in acute, subacute and chronic infections successively. This, in turn, facilitates the infectivity to new vectors, again allowing parasite dissemination in nature [28]. In addition to protecting the parasite against thermal stress, such proteins play an important role during the oxidative burst that occurs during infection of mammalian cells by $T$. cruzi $[21,25]$. During this process, the parasite is phagocytosed by macrophages and retained in parasitic vacuoles where they are attacked by lysosomal enzymes and reactive oxygen species. Thus, strain 452 (TcII) parasites can escape from the parasitic vacuole with greater ease, ensuring their intracellular life-cycle [21] by multiplying more intensely in the host and, consequently, resulting in higher levels of parasitemia $[8,26,27]$.

TDR1, also classified as a stress response protein and identified in the PR150 (TcI) strain, is homologous to TC52 protein in T. cruzi. This protein is also related to parasite's protection against oxidative stress during host cell infection [29]. A study that evaluated TDR1 expression in different strains of T. cruzi submitted to treatment with benznidazole observed higher expression in 
Table 1 Identities associated with differentially expressed proteins in the comparison between Tcl and Tcll genotypes

\begin{tabular}{|c|c|c|c|c|c|c|c|}
\hline Spot no./Strain & Accession number & Description & Gene & $\begin{array}{l}\text { Unique } \\
\text { peptides }\end{array}$ & Coverage (\%) & $\mathrm{pl}$ & $\begin{array}{l}\text { Observed } \\
\text { MW (kDa) }\end{array}$ \\
\hline \multicolumn{8}{|c|}{ Translation/Transcription } \\
\hline 22/PR150 & TCSYLVIO_990036 & Elongation factor 2 & EF2 & 31 & 42.25 & 6.04 & 75.70 \\
\hline 101/PR150 & TcCLB.503419.50 & RNA-binding protein RGGm & $R G G 2$ & 8 & 27.51 & 8.76 & 34.45 \\
\hline 139/PR150 & TcCLB.506925.130 & Eukaryotic translation initiation factor $5 a$ & EIF5A & 7 & 58.68 & 5.00 & 9.88 \\
\hline $56 / 452$ & TCCLB.509583.10 & Chaperonin TCP20 & TP20 & 22 & 41.07 & 7.69 & 51.11 \\
\hline $72 / 452$ & TCSYLVIO_002198 & Elongation factor 1-alpha (EF-1-alpha) & EF1A & 1 & 44.79 & 8.98 & 43.99 \\
\hline \multicolumn{8}{|c|}{ Heat-shock response } \\
\hline 28/PR150 & TCSYLVIO_008621 & Heat shock protein 85 & HSP85 & 6 & 10.99 & 6.35 & 73.76 \\
\hline 43/PR150 & TCSYLVIO_004969 & Chaperonin HSP60, mitochondrial precursor & HSP60 & 44 & 66.55 & 5.50 & 65.35 \\
\hline 44/PR150 & TCSYLVIO_004969 & Chaperonin HSP60, mithocondrial precursor & HSP6O & 36 & 75.09 & 5.50 & 65.35 \\
\hline 71/PR150 & TCSYLVIO_004831 & Thiol-dependent reductase 1 & TDR1 & 11 & 36.63 & 5.97 & 46.04 \\
\hline $26 / 452$ & TcCLB.507713.30 & Heat-shock protein 85 & HSP85 & 33 & 43.18 & 5.15 & 74.41 \\
\hline $35 / 452$ & TCCLB.511211.170 & Heat-shock protein 70 (HSP70) & HSP70 & 6 & 48.01 & 5.57 & 69.23 \\
\hline $41 / 452$ & TCSYLVIO_003281 & Heat-shock 70 kDa protein, mithocondrial precursor & HSP70 & 33 & 46.56 & 6.13 & 67.29 \\
\hline $42 / 452$ & TCSYLVIO_003281 & Heat-shock 70 kDa protein, mithocondrial precursor & HSP70 & 15 & 27.94 & 6.13 & 66.00 \\
\hline $125 / 452$ & TcCLB.506207.50 & IgE-dependent histamine-releasing factor & HRF & 4 & 16.47 & 4.64 & 18.35 \\
\hline $131 / 452$ & TcCLB.506207.50 & IgE-dependent histamine-releasing factor & HRF & 6 & 21.18 & 4.64 & 16.00 \\
\hline $131 / 452$ & TcCLB.509775.40 & Iron superoxide dismutase & $S O D B$ & 3 & 56.65 & 8.60 & 16.00 \\
\hline $140 / 452$ & TcCLB.503.899.130 & Glutathione peroxidase-like protein & GPX & 8 & 39.33 & 6.00 & 8.47 \\
\hline \multicolumn{8}{|l|}{ Cell signalling } \\
\hline $105 / 452$ & TcCLB.503855.20 & Spermidine synthase & SPSYN & 1 & 35.14 & 5.41 & 27.61 \\
\hline $140 / 452$ & TcCLB.503715.30 & Ras-related protein RAB1A & $R A B 1 A$ & 3 & 15.71 & 7.77 & 8.47 \\
\hline $143 / 452$ & TcCLB.511407.60 & Small GTP-binding protein RAB11 & $R A B 11$ & 7 & 43.78 & 8.13 & 3.36 \\
\hline \multicolumn{8}{|c|}{ Protein synthesis/Degradation } \\
\hline 59/PR150 & TCSYLVIO_005562 & Hypothetical protein (Metalocarboxypeptidase1) & MCP1 & 19 & 50.21 & 5.86 & 48.66 \\
\hline 108/PR150 & TCSYLVIO_001046 & Peptidase M20/M25/M40 & MT2598 & 8 & 17.78 & 5.43 & 27.61 \\
\hline 137/PR150 & TcCLB.507639.40 & Proteasome beta 5 subunit & PSMB5 & 9 & 27.01 & 5.90 & 13.47 \\
\hline $127 / 452$ & TCSYLVIO_005774 & Proteasome beta 2 subunit & PSMB2 & 9 & 24.66 & 9.19 & 18.35 \\
\hline \multicolumn{8}{|c|}{ Carbohydrate metabolism } \\
\hline 24/PR150 & TCSYLVIO_008551 & Pyruvate phosphate dikinase & PPDK & 3 & 37.18 & 6.73 & 75.05 \\
\hline 99/PR150 & TCSYLVIO_002700 & Cytosolic malate dehydrogenase & $\mathrm{MDH}$ & 9 & 35.24 & 6.73 & 34.45 \\
\hline $42 / 452$ & TCSYLVIO_004608 & Phosphoglycerate mutase & PGMI & 26 & 61.01 & 5.92 & 66.00 \\
\hline $51 / 452$ & TcCLB.507547.90 & Glycosomal phosphoenolpyruvate carboxykinase & PEPCK & 18 & 38.86 & 8.37 & 62.76 \\
\hline $106 / 452$ & TCCLB.510105.230 & Glyceraldehyde 3-phosphate dehydrogenase & GAPDH & 19 & 55.92 & 8.46 & 28.07 \\
\hline \multicolumn{8}{|c|}{ Nucleotide metabolism } \\
\hline 34/PR150 & TCSYLVIO_003291 & Tetrahydrofolate synthase & MTHFD1 & 10 & 16.67 & 7.68 & 69.23 \\
\hline $46 / 452$ & TcCLB.508731.60 & Adenylosuccinate synthetase & ADSS & 7 & 45.13 & 8.21 & 63.46 \\
\hline \multicolumn{8}{|c|}{ Aminoacid metabolism } \\
\hline 34/PR150 & TCSYLVIO_006380 & Urocanate hydratase & UROC1 & 10 & 14.67 & 6.86 & 69.23 \\
\hline 36/PR150 & TCSYLVIO_006380 & Urocanate hydratase & UROC1 & 16 & 20.74 & 6.86 & 69.23 \\
\hline 38/PR150 & TCSYLVIO_006380 & Urocanate hydratase & UROC1 & 37 & 44.74 & 6.86 & 68.58 \\
\hline 80/PR150 & TCSYLVIO_000769 & Tyrosine aminotransferase & TAT & 7 & 49.05 & 6.54 & 42.38 \\
\hline $56 / 452$ & TCSYLVIO_004599 & Histidine ammonia-lyase & HAL & 16 & 29.59 & 8.34 & 51.11 \\
\hline
\end{tabular}


Table 1 Identities associated with differentially expressed proteins in the comparison between Tcl and Tcll genotypes (Continued)

\begin{tabular}{|c|c|c|c|c|c|c|c|}
\hline Spot no./Strain & Accession number & Description & Gene & $\begin{array}{l}\text { Unique } \\
\text { peptides }\end{array}$ & Coverage (\%) & $\mathrm{pl}$ & $\begin{array}{l}\text { Observed } \\
\text { MW (kDa) }\end{array}$ \\
\hline $93 / 452$ & TCSYLVIO_001538 & Aspartate aminotransferase & GOT1 & 13 & 42.34 & 8.81 & 36.50 \\
\hline $111 / 452$ & TCSYLVIO_006042 & Arginase & $A R G$ & 12 & 54.22 & 6.46 & 25.88 \\
\hline $112 / 452$ & TCSYLVIO_003182 & Pyridoxal kinase & PDXK & 1 & 23.00 & 6.44 & 20.23 \\
\hline \multicolumn{8}{|l|}{ Lipid metabolism } \\
\hline $113 / 452$ & TCCLB.506213.50 & Prostaglandin F synthase & PGFS & 4 & 15.66 & 8.82 & 24.00 \\
\hline $115 / 452$ & TcCLB.511693.90 & Electron-transfer-flavoprotein, alpha polypeptide & ETFA & 4 & 57.01 & 8.27 & 24.00 \\
\hline $116 / 452$ & TcCLB.506213.50 & Prostaglandin F synthase & PGFS & 8 & 30.25 & 8.82 & 24.00 \\
\hline $118 / 452$ & TcCLB.510105.240 & Short chain 3-hydroxyacyl-coa dehydrogenase & HCD2 & 9 & 34.69 & 8.63 & 23.50 \\
\hline \multicolumn{8}{|l|}{ Cytoskeleton } \\
\hline 28/PR150 & TCSYLVIO_007343 & Calpain-like cysteine peptidase & $S M P-1$ & 10 & 15.03 & 5.05 & 73.76 \\
\hline $102 / 452$ & TCCLB.506563.40 & Beta tubulin & TUBB & 9 & 33.26 & 4.81 & 29.92 \\
\hline $142 / 452$ & TCSYLVIO_008641 & Epsilon tubulin & TUBE1 & 6 & 15.58 & 6.52 & 7.05 \\
\hline
\end{tabular}

strains considered resistant to the specific treatment, typical of TcI samples [30]. The same authors also suggested that strains or clones that overexpress TDR1 can escape from the immune system more easily and have high virulence [7, 31].

Another important overexpressed protein in strain 452 (TcII) is IgE-dependent histamine-releasing factor. This protein has been linked to the ability of parasites to generate chronic inflammation [32]. This increase in expression may explain the pronounced ability of this strain to generate inflammation in the cardiac tissue of infected mice, both in the acute and chronic phases of infection [10]. In humans, TcII parasites cause more marked pathology due to inflammation later replaced by fibrosis, mainly in the heart $[33,34]$. In addition, the expression of this gene has been associated with chronic inflammatory processes of the airways, such as allergic responses and asthmatic symptoms [35].

The enzymes SODB and GPX, both overexpressed in the TcII strain (452), confer protection against oxidative stress. Their expression is frequently related to an amplified immune response and consequent generation of

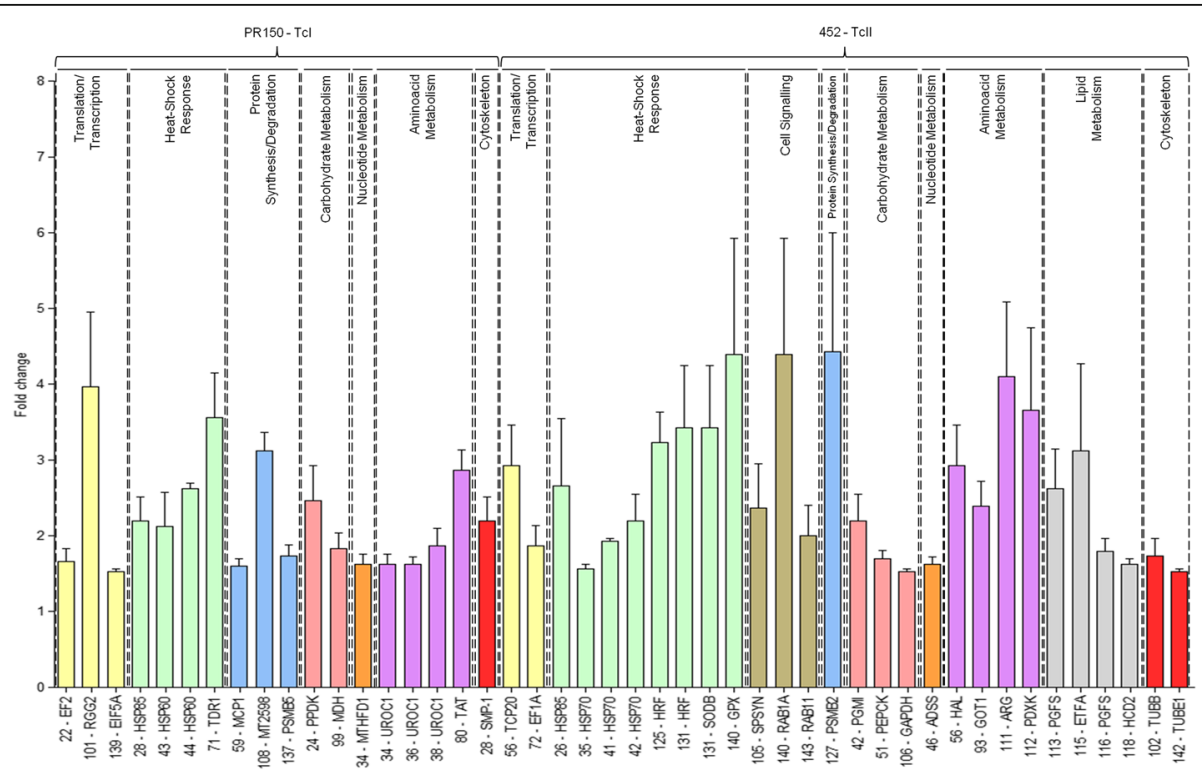

Fig. 2 Fold changes associated with differentially expressed proteins in the comparison between TCl (PR150) and Tcll (452) genotypes. Spot volumes associated with the differentially expressed proteins were processed by the SameSpots software and the ratio obtained between them, for corresponding spots in each gel, provided its respective fold change. The gel spots from sample 452 were taken as reference. Only positive fold values are shown and protein identities associated with each genotype are grouped (in curly brackets) 
reactive oxygen species, justifying their relevance in the pathogenesis of Chagas disease [36, 37].

The SOD enzymes catalyze the conversion of superoxide radicals $\left(\mathrm{O}_{2}^{-}\right)$into oxygen $\left(\mathrm{O}_{2}\right)$ and hydrogen peroxide $\left(\mathrm{H}_{2} \mathrm{O}_{2}\right)$. Thus, for $T$. cruzi parasites they provide the ability to withstand the highly oxidative environment rich in NADPH oxidase and nitric oxide synthase found in macrophages during phagocytosis [38]. It was demonstrated by Martinez et al. [39] and Piacenza et al. [40] that expression of SODB isoform correlates with high levels of resistance to oxidant treatment when compared to other isoforms (SODA and SODC) found in $T$. cruzi.

In terms of central metabolic pathways we observed increased expression of proteins linked to the metabolism of amino acids [histidine ammonia lyase (HAL), aspartate aminotransferase (GOT1), arginase (ARG) and pyridoxal kinase PDXK)] and lipids [prostaglandin Fsynthase (PGFS), electron transfer flavoprotein (ETFA) and 3-hydroxyacyl-Coa dehydrogenase (HCD2)] in the TcII strain (452) relative to the TcI strain (PR150).

Trypanosomatids alternate the main form of energy production according to the availability of substrates found in the environment. When sugar is available, $T$. cruzi uses aerobic fermentation to metabolize it. However, whenever needed, it can activate the mitochondrial pathway and oxidize amino acids with the concomitant production of ammonia for energy generation [41-43]. It is also postulated that amino acid metabolism is involved with the cytosolic reoxidation of NADH and the recycling of methionine [44]. The amino acid proline appears to be very closely associated with $T$. cruzi metacyclogenesis when the parasite is present on a nutrientpoor environment (e.g. absence of blood supply in the vector) or an aged culture medium [22, 45].

Glutamate is also another important amino acid used in oxidative metabolism and histidine is one of its precursors [41]. The biochemical pathway involved in such conversion employs some of the enzymes identified in this work as HAL and UROC1; these are commonly found overexpressed in the T. cruzi stages involving the insect vector [46]. Proline, another amino acid metabolically related to glutamate, seems to contribute through the supply of energy, allowing parasite growth in energetically unfavorable environments [47]. Additionally, proline has been linked to resistance to oxidative stress [48]. Aspartate aminotransferases carry out amino acid transamination producing 2-oxo acids used up in the Citric acid cycle. In addition, they apparently have the ability to convert 2-oxo-4-methylbutyrate to methionine, thus participating in the protection against oxidative stress [49, 50].

Arginase is one of the enzymes responsible for competing with iNOS to counterbalance the defensive action of
$\mathrm{NO}$ in infectious diseases by promoting parasite proliferation and differentiation. In addition, the enzyme suppresses $\mathrm{T}$ cell response through the production of polyamines with anti-inflammatory and immunosuppressive activities and influences, through arginine metabolism, the relationship between innate and acquired immune responses [51-53]. Although arginase activity has proven essential for $T$. cruzi infection, our study provides relevant data on the differential expression of this enzyme associated to a specific genotype. This observation merits attention and could have implications for the proposal of novel therapeutic approaches (e.g. arginase inhibitors) for patients harboring parasites belonging to distinct DTUs.

Overexpression of the PDXK enzyme associated with the TcII strain is also of interest. It is involved in the production of vitamin B6 (pyridoxal 5'-phosphate) from its precursors pyridoxal, pyridoxamine and pyridoxine [54]. This vitamin is a coenzyme for transaminases, assuming a crucial role in transamination, decarboxylation, racemization and amino acid substitution reactions, as well as being implicated in the antioxidant defense [55].

As for lipid metabolism, ETFA and HCD2 proteins are involved in the generation of ATP through $\beta$-oxidation of fatty acids. In its turn, PGFS oxidoreductase plays an important role in evasion of the host immune response through prostaglandin synthesis, as demonstrated in Leishmania infantum by Araújo-Santos et al. [56]. The ability of $T$. cruzi to metabolize arachidonic acid into eicosanoids has been demonstrated to play an important role in parasite invasion and survival in the host [57-60].

Our comparative 2D-gel electrophoresis provided a reliable tool to visualize and measure pronounced differences in protein expression associated to distinct $T$. cruzi genotypes (TcI and TcII), isolated from chronically infected patients displaying the cardiac form of $\mathrm{CD}$. The high levels of proteins associated to stress response and the key aspects of amino acid and lipid pathways overrepresented in the TcII genotype might contribute to explain the differential biological behavior observed for strain 452 during our preliminary in vitro and in vivo studies [10].

\section{Conclusions}

Here we have expanded the repertoire of protein molecules distinctly expressed in the two $T$. cruzi genotypes mostly associated to disease in South America, particularly in the Brazilian population [59]. The search for effective methods to analyze and compare the proteomes of $T$. cruzi strains may be fundamental to show the association between the parasite's genetic variability and the 
clinical manifestations resulting from the infection. Profiling the differential proteome of the distinct $T$. cruzi genotypes may shed light on novel approaches for prognosis and clinical management of those affected by Chagas disease.

\section{Additional file}

Additional file 1: Table S1. Protein/peptide mass spectrometry data and derived parameters. (XLSX $110 \mathrm{~kb}$ )

\section{Abbreviations}

1D: One dimensional; 2D: Two-dimensional; ACN: Acetonitrile; ADSS: Adenylosuccinate synthetase; ARG: Arginase; AUC: Area Under Curve; CD: Chagas disease; CHAPS: 3-[(3-cholamidopropyl)dimethylammonio]-1propanesulfonate; DTT: 1,4-dithiothreitol; DTUs: Chagas disease discrete typing units; DTUs: Discrete typing units; EF1A: Elongation factor 1-alpha; EF2: Elongation factor 2; EIF5A: Eukaryotic translation initiation factor 5a; ETFA: Electron transfer flavoprotein; GAPDH: Glyceraldehyde 3-phosphate dehydrogenase; GOT1: Aspartate aminotransferase; GPX: Glutathione peroxidase-like protein; HAL: Histidine ammonia lyase; HCD: Higher-energy collisional dissociation; HCD2: 3-hydroxyacyl-Coa dehydrogenase; HRF: IgEdependent histamine-releasing factor; HSP'S: Heat-shock proteins; IPG: Immobilized pH gradient; LIT: Liver infusion triptose; MCP1: Metalocarboxypeptidase1; MDH: Cytosolic malate dehydrogenase; MG: Minas Gerais; MS/ MS: Tandem mass spectrometry; MT2598: Peptidase M20/M25/M40; MTHFD1: Tetrahydrofolate synthase; NL: Nonlinear; NO: Nitric oxide; PBS: Sterile buffered saline; PDXK: Pyridoxal kinase; PEPCK: Glycosomal phosphoenolpyruvate carboxykinase; PGFS: Prostaglandin F synthase PGMI: Phosphoglycerate mutase; PPDK: Pyruvate phosphate dikinase; PSMB's: Proteasome beta subunits; RAB11: Small GTP-binding protein RAB11; RAB1A: Ras-related protein; RBC: Red blood cell; RGG2: RNAbinding protein RGGm; SDS-PAGE: Sodium dodecyl sulfate polyacrylamide ge electrophoresis; SMP-1: Calpain-like cysteine peptidase; SODB: Iron superoxide dismutase; SPSYN: Spermidine synthase; TAT: Tyrosine aminotransferase; TDR1: Thiol-dependent reductase 1; TFA: Trifluoracetic acid; TP20: Chaperonin TCP20; TUBs: Tubulins; UROC1: Urocanate hydratase; WHO: World Health Organization

\section{Acknowledgements}

The authors would like to acknowledge the technical support provided by Bruno Mattei from the Proteomics facility at NUPEB/UFOP.

\section{Funding}

$M L$ received funding from 'Fundação de Amparo à Pesquisa do Estado de Minas Gerais' (Fapemig), grant number APQ-00766-16. WCB received funding from Fapemig grant number APQ-03367-16. MTO was a recipient of a CAPES scholarship for the funding of his PhD in Biological Sciences at NUPEB/UFOP.

\section{Availability of data and materials}

The datasets generated and analysed during the present study are available in the ProteomeXchange repository through the following link: http:// proteomecentral.proteomexchange.org/cgi/GetDataset?ID=PXD011172.

\section{Authors' contributions}

MTO and KTSS conceived, designed, carried out experiments, analysed data and drafted the manuscript. LXN provided technical support for mass spectrometric identification and data analysis. MJOT provided the $\mathrm{TCl}$ sample for analysis and helped in the discussion of results. WCB and $\mathrm{ML}$ conceived and designed the experiments, analysed data and drafted the manuscript. All authors read and approved the final manuscript.

\section{Ethics approval and consent to participate}

Patients who agreed to participate in the Chagas Disease Program signed a Free and Informed Consent Form approved by the Research Ethics Committee in Human Research Center René Rachou, Fiocruz, Belo Horizonte, MG (protocol number 007/2002).

\section{Consent for publication}

Written informed consent was obtained from the study participants to publish findings from the study.

\section{Competing interests}

The authors declare that they have no competing interests.

\section{Publisher's Note}

Springer Nature remains neutral with regard to jurisdictional claims in published maps and institutional affiliations.

\section{Author details}

1Programa de Pós-Graduação em Ciências Biológicas do Núcleo de Pesquisas em Ciências Biológicas (NUPEB), Campus Universitário Morro do Cruzeiro, Universidade Federal de Ouro Preto, CEP, Ouro Preto, MG 35400-000, Brazil. ${ }^{2}$ Departamento de Farmácia, Escola de Farmácia, Campus Universitário Morro do Cruzeiro, Universidade Federal de Ouro Preto, CEP, Ouro Preto, MG 35400-000, Brazil. PPrograma de Pós-Graduação em Biotecnologia do Núcleo de Pesquisas em Ciências Biológicas (NUPEB), Campus Universitário Morro do Cruzeiro, Universidade Federal de Ouro Preto, CEP: 35400-000, Ouro Preto, MG, Brazil. " Departamento de Ciências Básicas da Saúde - Parasitologia, Universidade Estadual de Maringá, CEP: 87020-900, Maringá, Paraná, PR, Brazil. ${ }^{5}$ Departamento de Ciências Biológicas, Instituto de Ciências Exatas e Biológicas, Campus Universitário Morro do Cruzeiro, Universidade Federal de Ouro Preto, CEP: 35400-000, Ouro Preto, MG, Brazil. ${ }^{\circ}$ Departamento de Análises Clínicas, Escola de Farmácia, Campus Universitário Morro do Cruzeiro, Universidade Federal de Ouro Preto, CEP: 35400-000, Ouro Preto, MG, Brazil.

Received: 2 July 2018 Accepted: 31 October 2018

Published online: 29 November 2018

References

1. WHO. Chagas disease (American trypanosomiasis). Geneva: World Health Organization; 2018. http://www.who.int/news-room/fact-sheets/detail/ chagas-disease-(american-trypanosomiasis). Accessed 19 June 2018.

2. Díaz ML, Solari A, González Cl. Differential expression of Trypanosoma cruzi associated with clinical forms of Chagas disease: overexpression of oxidative stress proteins in acute patient isolate. J Proteomics. 2011;74:1673-82.

3. Dost CK, Albuquerque S, Hemleben V, Engels W, Prado JC Jr. Molecular genetic characterization of different Trypanosoma cruzi strains and comparison of their development in Mus musculus and Calomys callosus. Parasitol Res. 2002;88:609-16.

4. Vago AR, Andrade LO, Leite AA, d'Avila Reis D, Macedo AM, Adad SJ, et al. Genetic characterization of Trypanosoma cruzi directly from tissues of patients with chronic Chagas disease: differential distribution of genetic types into diverse organs. Am J Pathol. 2000;156:1805-9.

5. Telleria J, Biron DG, Brizard JP, Demettre E, Séveno M, Barnabé C, et al. Phylogenetic character mapping of proteomic diversity shows high correlation with subspecific phylogenetic diversity in Trypanosoma cruzi. Proc Natl Acad Sci USA. 2010;107:20411-6.

6. Zingales B. Trypanosoma cruzi genetic diversity: something new for something known about Chagas disease manifestations, serodiagnosis and drug sensitivity. Acta Trop. 2018;184:38-52.

7. Toledo MJ, Lana M, Carneiro CM, Bahia MT, Machado-Coelho GL, Veloso VM, et al. Impact of Trypanosoma cruzi clonal evolution on its biological properties in mice. Exp Parasitol. 2002;100:161-72.

8. Andrade SG, Magalhães JB. Biodemes and zymodemes of Trypanosoma cruz strains: correlations with clinical data and experimental pathology. Rev Soc Bras Med Trop. 1997;30:27-35.

9. Zingales B, Miles MA, Campbell DA, Tibayrenc M, Macedo AM, Teixeira MM, et al. The revised Trypanosoma cruzi subspecific nomenclature: rationale, epidemiological relevance and research applications. Infect Genet Evol. 2012;12:240-53.

10. de Oliveira GS, Kawahara R, Rosa-Fernandes L, Mule SN, Avila CC, Teixeira MMG, et al. Development of a Trypanosoma cruzi strain typing assay using MS2 peptide spectral libraries (TC-STAMS2). PLoS Negl Trop Dis. 2018;12: e0006351.

11. Oliveira MT, Branquinho RT, Alessio GD, Mello CGC, Nogueira-de-Paiva NC, Carneiro CM, et al. Tcl, Tcll and TcVl Trypanosoma cruzi samples from Chagas disease patients with distinct clinical forms and critical analysis of in 
vitro and in vivo behavior, response to treatment and infection evolution in murine model. Acta Trop. 2017;167:108-20.

12. Teston AP, Monteiro WM, Reis D, Bossolani GD, Gomes ML, de Araújo SM, et al. In vivo susceptibility to benznidazole of Trypanosoma cruzi strains from the western Brazilian Amazon. Trop Med Int Health. 2013;18:85-95.

13. Oliveira MT, De Assis GF, Oliveira e Silva JC, Machado EM, Da Silva GN, Veloso VM, et al. Trypanosoma cruzi Discrete Typing Units (Tcll and $\mathrm{TCVI}$ ) in samples of patients from two municipalities of the Jequitinhonha Valley, MG, Brazil, using two molecular typing strategies. Parasit Vectors. 2015;31:568.

14. Ministério da Saúde. Secretaria de Vigilância em Saúde. Brazilian Consensus on Chagas disease. Rev Soc Bras Med Trop. 2005;38:7-29.

15. WHO. Control of Chagas disease. Technical Report Series, vol. 905. Geneva: World Health Organization; 2002.

16. Dias JC, Ramos AN Jr, Gontijo ED, Luquetti A, Shikanai-Yasuda MA, Coura JR, et al. Second Brazilian consensus on Chagas disease. 2015. Rev Soc Bras Med Trop. 2016:49:3-60.

17. Chiari E, Dias JC, Lana M, Chiari CA. Hemocultures for the parasitological diagnosis of human chronic Chagas' disease. Rev Soc Bras Med Trop. 1989;22:19-23.

18. Camargo EP. Growth and differentiation in Trypanosoma cruzi. I. Origin of metacyclic trypanosomes in liquid media. Rev Inst Med Trop São Paulo. 1964;6:93-100

19. Braga MS, Neves LX, Campos JM, Roatt BM, de Oliveira Aguiar Soares RD, Braga SL, et al. Shotgun proteomics to unravel the complexity of the Leishmania infantum exoproteome and the relative abundance of its constituents. Mol Biochem Parasitol. 2014;195:43-53.

20. Hellman V, Wernstedt C, Gonez J, Heldin CH. Improvement of an "in-gel" digestion procedure for the micropurification of internal protein fragments for amino acid sequencing. Anal Biochem. 1995;224:451-5.

21. Urményi TP, Silva R, Rondinelli E. The heat shock proteins of Trypanosoma cruzi. Subcell Biochem. 2014;74:119-35.

22. Contreras VT, Salles JM, Thomas N, Morel CM, Goldenberg S. In vitro differentiation of Trypanosoma cruzi under chemically defined conditions. Mol Biochem Parasitol. 1985;16:315-27.

23. Shonhai A, Maier AG, Przyborski JM, Blatch GL. Intracellular protozoan parasites of humans: the role of molecular chaperones in development and pathogenesis. Protein Pept Lett. 2011;18:143-57.

24. Richter $\mathrm{K}$, Haslbeck $M$, Buchner J. The heat shock response: life on the verge of death. Mol Cell. 2010;40:253-66.

25. Folgueira C, Requena JM. A postgenomic view of the heat shock proteins in kinetoplastids. FEMS Microbiol Rev. 2007;31:359-77.

26. Oliveira-Silva JC, Machado-de Assis GF, Oliveira MT, Paiva NC, Araújo MS, Carneiro CM, et al. Experimental benznidazole treatment of Trypanosoma cruzi II strains sampled from children of the Jequitinhonha Valley, Minas Gerais, Brazil, with Chagas disease. Mem Inst Oswaldo Cruz. 2015;11:86-94.

27. Carneiro M, Antunes CM. Evaluation of the efficacy of the Chagas' Disease Control Program: methodological aspects. Cad Saude Publica. 1994;10:261-72

28. Alessio GD, Araujo FF, Côrtes DF, Sales Junior PA, Lima DC, Gomes MS, et al. Performance of $\mathrm{TCl} / \mathrm{TCV} / \mathrm{Tcll}$ Chagas-Flow ATE-lgG2a for universal and genotype-specific serodiagnosis of Trypanosoma cruzi infection. PLoS Negl Trop Dis. 2017;11:e0005444.

29. Silva AM, Tavares J, Silvestre R, Ouaissi A, Coombs GH, Cordeiro-da-Silva A. Characterization of Leishmania infantum thiol-dependent reductase 1 and evaluation of its potential to induce immune protection. Parasite Immunol. 2012;34:345-50

30. Toledo MJ, Bahia MT, Carneiro CM, Martins-Filho OA, Tibayrenc M, Barnabé $C$, et al. Chemotherapy with benznidazole and itraconazole for mice infected with different Trypanosoma cruzi clonal genotypes. Antimicrob Agents Chemother. 2003:47:223-30.

31. Garzón M, García-Fructuoso G, Guillén A, Sunõl M, Mora J, Cruz O. Brain stem tumors in children and adolescents: single institutional experience. Childs Nerv Syst. 2013;29:1321-31.

32. MacDonald SM. Human recombinant histamine-releasing factor. Int Arch Allergy Immunol. 1997;113:187-9.

33. Andrade LO, Galvão LM, Meirelles MN, Chiari E, Pena SD, Macedo AM. Differential tissue tropism of Trypanosoma cruzi strains: an in vitro study. Mem Inst Oswaldo Cruz. 2010;105:834-7.

34. Toledo MJ, Bahia MT, Veloso VM, Carneiro CM, Machado-Coelho GL, Alves $C F$, et al. Effects of specific treatment on parasitological and histopathological parameters in mice infected with different Trypanosoma cruzi clonal genotypes. J Antimicrob Chemother. 2004; 53:1045-53.

35. Kashiwakura J, Okayama Y, Furue M, Kabashima K, Shimada S, Ra C, et al. Most highly cytokinergic IgEs have polyreactivity to autoantigens. Allergy Asthma Immunol Res. 2012:4:332-40.

36. Budni P, Pedrosa RC, Dalmarco EM, Dalmarco JB, Frode TS, Wilhelm Filho D. Carvedilol enhances the antioxidant effect of vitamins $E$ and $C$ in chronic Chagas heart disease. Arq Bras Cardiol. 2013;101:304-10.

37. Dhiman M, Coronado YA, Vallejo CK, Petersen JR, Ejilemele A, Nuñez S, et al. Innate immune responses and antioxidant/oxidant imbalance are major determinants of human Chagas disease. PLoS Negl Trop Dis. 2013;7:e2364.

38. Alvarez MN, Peluffo G, Piacenza L, Radi R. Consequences for oxidative killing and role of microbial peroxiredoxin infectivity. J Biol Chem. 2011;286: 6627-40.

39. Martinez A, Peluffo G, Petruk AA, Hugo M, Piñeyro D, Demicheli V, et al. Structural and molecular basis of the peroxynitrite-mediated nitration and inactivation of Trypanosoma cruzi iron-superoxide dismutases (Fe-SODs) A and B. J Biol Chem. 2014:289:12760-78.

40. Piacenza L, Peluffo G, Alvarez MN, Martínez A, Radi R. Trypanosoma cruzi antioxidant enzymes as virulence factors in Chagas disease. Antioxid Redox Signal. 2013;19:723-34.

41. Barisón MJ, Damasceno FS, Mantilla BAS, Silber AM. The active transport of histidine and its role in ATP production in Trypanosoma cruzi. J Bioenerg Biomembr. 2016:48:437-49.

42. Cazzulo JJ. Intermediate metabolism in Trypanosoma cruzi. J Bioenerg Biomembr. 1994;26:157-65.

43. Cazzulo JJ, Franke de Cazzulo BM, Engel JC, Cannata JJ. End products and enzyme levels of aerobic glucose fermentation in trypanosomatids. Mol Biochem Parasitol. 1985;16:329-43.

44. Blankenfeldt W, Nowicki C, Montemartini-Kalisz M, Kalisz HM, Hecht H. Crystal structure of Trypanosoma cruzi tyrosine aminotransferase: substrate specificity is influenced by cofactor binding mode. Protein Sci. 1999:8:2406-17.

45. Bonaldo MC, Souto-Padron T, de Souza W, Goldenberg S. Cell-substrate adhesion during Trypanosoma cruzi differentiation. J Cell Biol. 1988;106: 1349-58.

46. Minning TA, Weatherly DB, Atwood J 3rd, Orlando R, Tarleton RL. The steady-state transcriptome of the four major life-cycle stages of Trypanosoma cruzi. BMC Genomics. 2009;7:370.

47. Mantilla BS, Marchese L, Casas-Sánchez A, Dyer NA, Ejeh N, Biran M, et al. Proline metabolism is essential for Trypanosoma brucei brucei survival in the tsetse vector. PLoS Pathog. 2017;13:e1006158.

48. Magdaleno A, Suárez Mantilla B, Rocha SC, Pral EM, Silber AM. The involvement of glutamate metabolism in the resistance to thermal, nutritional, and oxidative stress in Trypanosoma cruzi. Enzyme Res. 2011; 2011:486928.

49. Marciano D, Llorente C, Maugeri DA, Fuente C, Opperdoes F, Cazzulo JJ, et al. Biochemical characterization of stage-specific isoforms of aspartate aminotransferases from Trypanosoma cruzi and Trypanosoma brucei. Mol Biochem Parasitol. 2008;161:12-20.

50. Canepa GE, Bouvier LA, Urias U, Miranda MR, Colli W, Alves MJM, et al. Aspartate transport and metabolism in the protozoan parasite Trypanosoma cruzi. FEMS Microbiol Lett. 2005;247:65-71.

51. Balaña-Fouce R, Calvo-Álvarez E, Álvarez-Velilla R, Prada CF, Pérez-Pertejo Y, Reguera RM. Role of trypanosomatid's arginase in polyamine biosynthesis and pathogenesis. Mol Biochem Parasitol. 2012;181:85-93.

52. Dulgerian LR, Garrido W, Stempin CC, Cerba'n FM. Programmed death ligand 2 regulates arginase induction and modifies Trypanosoma cruzi survival in macrophages during murine experimental infection. Immunology. 2011;133:29-40.

53. Peranzoni E, Marigo I, Dolcetti L, Ugel S, Sonda N, Taschin E, et al. Role of arginine metabolism in immunity and immunopathology. Immunobiology. 2007:212:795-812

54. Kimura T, Shirakawa R, Yaoita N, Hayashi T, Nagano K, Horiuchi H. The antimalarial drugs chloroquine and primaquine inhibit pyridoxal kinase, an essential enzyme for vitamin B6 production. FEBS Lett. 2014:588:3673-6.

55. Jones DC, Alphey MS, Wyllie S, Fairlamb AH. Chemical, genetic and structural assessment of pyridoxal kinase as a drug target in the African trypanosome. Mol Microbiol. 2012;86:51-64. 
56. Araújo-Santos T, Rodríguez NE, Moura-Pontes S, Dixt UG, Abánades DR, Bozza PT, et al. Role of prostaglandin F2a production in lipid bodies from Leishmania infantum chagasi: insights on virulence. J Infect Dis. 2014;210: 1951-61.

57. Moraes KCM, Diniz LF, Bahia MT. Role of cyclooxygenase-2 in Trypanosoma cruzi survival in the early stages of parasite host-cell interaction. Mem Inst Oswaldo Cruz. 2015;110:181-91.

58. Mukherjee S, Machado FS, Huang H, Oz HS, Jelicks LA, Prado CM, et al. Aspirin treatment of mice infected with Trypanosoma cruzi and implications for the pathogenesis of Chagas disease. PLoS One. 2011;6:e16959.

59. Brenière SF, Waleckx E, Barnabé C. Over six thousand Trypanosoma cruzi strains classified into discrete typing units (DTUs): attempt at an inventory. PLoS Negl Trop Dis. 2016;10:e0004792.

60. Mazet M, Harijan RK, Kiema TR, Haapalainen AM, Morand P, Morales J, et al. The characterization and evolutionary relationships of a trypanosomal thiolase. Int J Parasitol. 2011;41:1273-83.

- fast, convenient online submission

- thorough peer review by experienced researchers in your field

- rapid publication on acceptance

- support for research data, including large and complex data types

- gold Open Access which fosters wider collaboration and increased citations

- maximum visibility for your research: over $100 \mathrm{M}$ website views per year

At BMC, research is always in progress.

Learn more biomedcentral.com/submissions 